\title{
COMPARISON OF SEROLOGICAL TESTS AND PCR FOR DIAGNOSIS OF HUMAN BRUCELLOSIS SUFFERING FROM FEVER
}

\author{
PRABIR KUILA, DEVARATI DUTTA, URMITA CHAKRABARTY, DEBASMITA CHATTERJEE, SATADAL DAS*
}

Department of Microbiology, DBT Brucella Research Laboratory, Peerless Hospital and B. K. Roy Research Centre, Kolkata, West Bengal, India. Email: drsatdas@hotmail.com

Received: 10 January 2017, Received and Accepted: 08 February 2017

\section{ABSTRACT}

Objective: Brucellosis is an important zoonotic disease throughout the globe and other developing countries. The present study was aimed to compare results of different serological tests and polymerase chain reaction (PCR) for diagnosis of brucellosis in patients suffering from fever in Kolkata and in adjoining districts.

Methods: A total of 2088 serum samples were collected from the patients suffering from fever from January, 2013, to September, 2015. The samples were tested by serological tests, serum tube agglutination test (STAT), Rose Bengal plate test (RBPT), enzyme-linked immunosorbent assay (ELISA) (immunoglobulin M [IgM] and immunoglobulin G [IgG]), and Brucella genus-specific PCR.

Results: The study revealed decreasing positive results by STAT (18.43\%, N=385), RBPT (12.59\%, N=263), IgM ELISA (7.71\%, N=161), PCR (4.21\%, $\mathrm{N}=88)$, and IgG ELISA (1.43\%, N=30). When serological tests were compared with PCR, it was found that both STAT and PCR were positive in 84 samples (4.02\%), both RBPT and PCR were positive in 65 samples (3.11\%), both IgM and PCR were positive in 51 samples (2.44\%), and both IgG and PCR were positive in 9 samples $(0.43 \%)$.

Conclusion: In this cross-sectional study in a zonal population of India, it was found that STAT was the most sensitive test for diagnosis of brucellosis followed by RBPT when compared to PCR test results. Four STAT-negative samples showed positive results in PCR, which were positive by RBPT test. This indicates that if we combine STAT and RBPT for diagnosis of brucellosis, then both sensitivity and specificity of the combined test will increase.

Keywords: Brucellosis, Serum tube agglutination test, Rose Bengal plate test, Enzyme-linked immunosorbent assay, Genus-specific polymerase chain reaction.

(C) 2017 The Authors. Published by Innovare Academic Sciences Pvt Ltd. This is an open access article under the CC BY license (http://creativecommons. org/licenses/by/4. 0/) DOI: http://dx.doi.org/10.22159/ajpcr.2017.v10i5.17016

\section{INTRODUCTION}

Brucellosis is a widespread zoonosis which causes a significant health problem in both humans and animals. The causative agent of brucellosis is bacteria of genus Brucella. It is facultative, gram-negative, non-sporeforming, non-capsulated, intracellular coccobacilli. It infects animals first and then transmits to humans. Among all the species of Brucella, Brucella melitensis and Brucella abortus are the main causative agent of human brucellosis. In India, the other species Brucella suis and Brucella canis rarely cause human disease [1,2]. Brucellosis is endemic in various countries, particularly in developing countries throughout the globe.

Brucellosis has various clinical symptoms such as prolonged fever, night sweat and weight loss. One of the most important causes of pyrexia of unknown origin is brucellosis. The clinical manifestations of human brucellosis often show similarity with other diseases. Hence, it is necessary to diagnose brucellosis properly. There are several laboratory tests to diagnose brucellosis such as serological tests which include serum tube agglutination test (STAT), Rose Bengal plate test (RBPT), enzyme-linked immunosorbent assay (ELISA), and molecular test such as polymerase chain reaction (PCR) as well as the most difficult Brucella blood culture technique. There is no single serological test which can confirm the diagnosis of brucellosis. According to some, PCR is the golden test for brucellosis and also it is used as a predictive marker for the course of the disease [3-6].

The aim of the present study was to compare STAT, RBPT, ELISA, and PCR tests for diagnosis of human brucellosis in fever cases.

\section{METHODS}

For this study, permission of the Institutional Ethical Committee had been taken. At the time of investigation, all the patients had been informed about the aim of the study, and written consent had been taken from all of the patients. The study was done at Peerless Hospital and B.K Roy Research Centre in Kolkata, India. A total of 2088 blood samples were collected from the patients suffering from fever. The clinical manifestation of fever cases includes symptoms such as temperature greater than $38.3^{\circ} \mathrm{C}$ on several occasions within 3 weeks and failure to reach a diagnosis during this period. All the serum samples were stored in $-20^{\circ} \mathrm{C}$ until they were used.

\section{Serological tests}

STAT

STAT was performed using a commercial kit [Tulip Diagnostics (p) Ltd. Goa, India]. The kit contains ready to use standardized specific antigen suspensions of Brucella having specific reactivity toward antibodies to $B$. abortus and B. melitensis. The test was performed according to the company guidelines. At first, 8 test tubes were taken and numbered as 1-8. The test tube labeled with 8 was taken for negative control. The first test tube was filled up with $1.9 \mathrm{ml}$ phenol saline, and other 7 test tubes were filled up with $1 \mathrm{ml}$ phenol saline. Next, $0.1 \mathrm{ml}$ test serum was taken to the first test tube to get $1 / 20$ dilution. After that from first test tube, $1 \mathrm{ml}$ diluted serum sample was transferred to the $2^{\text {nd }}$ test tube, and this process was repeated from the $2^{\text {nd }}$ to $7^{\text {th }}$ test tubes to get $1 / 40,1 / 80,1 / 160,1 / 320,1 / 640$, and $1 / 1280$ dilutions. Next, 1 drop $(50 \mu \mathrm{L})$ of antigen was added to each test tube along with negative control and mixed. After that, all the test tubes were kept in incubator at $37^{\circ} \mathrm{C}$ for $24 \mathrm{hrs}$. An antibody titer of 1:160 and above was considered positive for brucellosis. 


\section{$R B P T$}

Rose Bengal antigen was procured from a commercial company (ID. vet innovative diagnostics, France). The antigen is used for detecting B. abortus (bovine)-, B. melitensis (ovine)-, or B. suis (swine)-specific antibodies in sera. The test was performed according to the company guidelines. $25 \mu \mathrm{L}$ of Rose Bengal antigen and an equivalent amount of serum were mixed up on a slide. After 4 minutes, if there is slight agglutination, the presence of specific antibodies was demonstrated by the formation of agglutinates that were visible to the naked eye. In the absence of specific antibodies, the mixture remains homogeneous.

\section{ELISA}

The Brucella ELISA test was performed using a commercial kit (Immunolab immunoglobulin M [IgM] and immunoglobulin G [IgG], Germany), and the procedure of the test was followed by the kit instruction. At first microtiter, wells (which are coated with Brucella antigen (B. abortus strain, w99) were filled up with $100 \mu \mathrm{L}$ each of the diluted (1:101) samples along with ready to use standards and controls except one well which was used for the substrate blank. Next, at the room temperature, the plate was incubated for $1 \mathrm{hr}$. After that, the wells were washed with the buffer solution. Next, $100 \mu \mathrm{L}$ ready to use conjugate was added to all the wells. Then, the plate was covered with enclosed foil and incubated at room temperature for 30 minutes. After that, the wells were washed with wash buffer, and $100 \mu \mathrm{L}$ each of the ready to use substrate was pipetted to all wells. Then, the plate was covered with the enclosed foil and incubated at room temperature for 20 minutes in the dark. Finally, $100 \mu \mathrm{L}$ stop solution pipetted to all the wells to stop the reaction. The plate was then subjected for reading at $450 \mathrm{~nm}$.

Extraction of genomic DNA followed by confirmation with Brucella genus-specific PCR

The genomic DNA extraction of the suspected human serum sample was done by Qiagen blood mini kit (Germany). All the procedures were followed as described by Ghatak et al. [7].

PCR was done (Fig. 1) with the reagent of Sigma company, and the primers were BCSP-B4(F)-TGGCTCGGTTGCCAATATCAA, BCSP-B5(R)CGCGCTTGCCTTTCAGGTCTG, and all the procedures were followed as described by Joshi et al. [8].

\section{RESULTS}

A total of 2088 samples were tested. The investigation revealed (Fig. 2) decreasing positive results by STAT $(18.43 \%, \mathrm{~N}=385)$, RBPT $(12.59 \%$, $\mathrm{N}=263)$, IgM ELISA (7.71\%, N=161), PCR (4.21\%, N=88), and IgG ELISA (1.43\%, N=30) (Fig. 2). Furthermore, when all the serological tests and PCR tests were compared, it was found that STAT and PCR together showed maximum number of positive cases (Table 1).

It was also found that both STAT and PCR were positive in 23 samples when all RBPT tests were negative. Both RBPT and PCR were positive in 4 samples when all STATs were negative. All the three tests, STAT, RBPT, and PCR, were positive found in 61 cases. It was also found that both IgM and PCR were positive in 47 cases when all IgG were negative. Furthermore, IgG and PCR both were positive in 5 cases when all IgM were negative. All the three tests- IgM, IgG and PCR were positive in 4 cases (Table 2).

\section{Sensitivity and specificity tests}

Specificity and sensitivity of all the serological tests were done with respect to PCR for measuring the test efficacy. The sensitivity of a test is defined as it is the capacity of test to detect positive cases or patient with disease who will have a positive result when compared with gold standard. Specificity is the capacity of the test to detect negative or nondiseased people who will have a negative result when compared with gold standard $[9,10]$. The sensitivity and specificity of all the test results considering PCR as gold standard are given in Table 3 and Fig. 3.

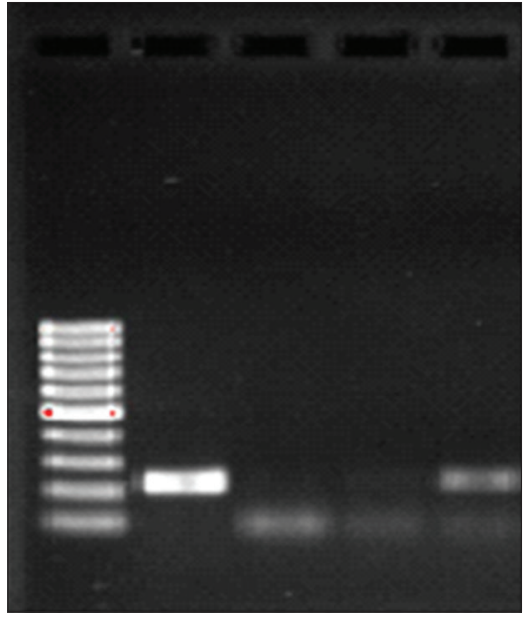

Fig. 1: The gel picture of polymerase chain reaction product. The $1^{\text {st }}$ lane $=100 \mathrm{bp}$ ladder. $2^{\text {nd }}$ lane $=$ positive control, $3^{\text {rd }}$ lane $=$ negative control, and $5^{\text {th }}$ lane $=$ sample positive

PERCENTAGE OF POSTTIVITY

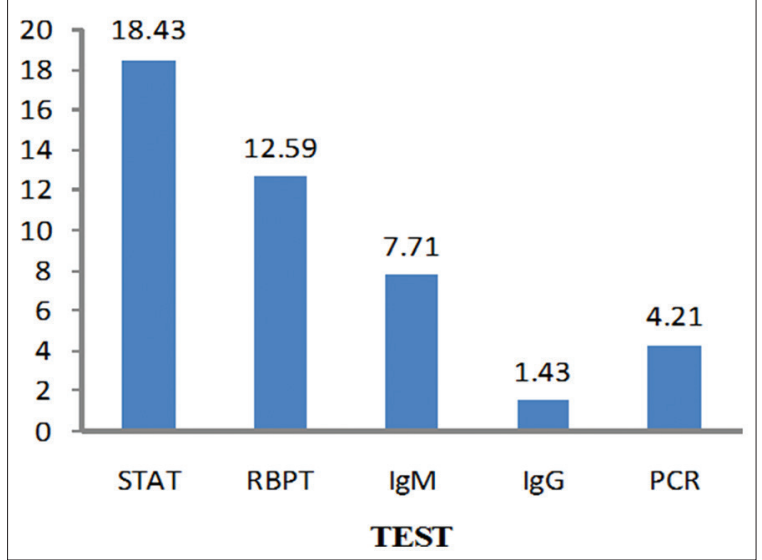

Fig. 2: The percentage of seropositivity and polymerase chain reaction positivity

Table 1: Both seropositive and PCR positive cases

\begin{tabular}{ll}
\hline Seropositive+PCR positive & n (\%) \\
\hline STAT+PCR & $84(4.02)$ \\
RBPT+PCR & $65(3.11)$ \\
IgM+PCR & $51(2.44)$ \\
IgG+PCR & $9(0.43)$ \\
\hline
\end{tabular}

STAT: Serum tube agglutination test, RBPT: Rose bengal plate test, PCR: Polymerase chain reaction, IgM: Immunoglobulin M, IgG: Immunoglobulin G

Table 2: Positivity patterns of PCR with other serological tests

\begin{tabular}{llll}
\hline STAT positive & RBPT negative & PCR positive & $23(1.10 \%)$ \\
STAT negative & RBPT positive & PCR positive & $4(0.19 \%)$ \\
STAT positive & RBPT positive & PCR positive & $61(2.9 \%)$ \\
IgM positive & IgG negative & PCR positive & $47(2.25 \%)$ \\
IgM negative & IgG positive & PCR positive & $5(0.23 \%)$ \\
IgM positive & IgG positive & PCR positive & $4(0.19 \%)$ \\
\hline
\end{tabular}

RBPT: Rose Bengal plate test, PCR: Polymerase chain reaction,

IgM: Immunoglobulin M, IgG: Immunoglobulin G, STAT: Serum tube agglutination test

\section{DISCUSSION}

Brucellosis shows overlapping clinical manifestation with other diseases. Diagnostic problems arise due its similar 0-antigen side chain 
Table 3: Sensitivity and specificity of serological tests when compared to PCR test

\begin{tabular}{|c|c|c|c|c|}
\hline \multirow[t]{2}{*}{ Tests } & \multicolumn{2}{|l|}{ PCR } & \multirow{2}{*}{$\begin{array}{l}\text { Sensitivity } \\
(\%)\end{array}$} & \multirow{2}{*}{$\begin{array}{l}\text { Specificity } \\
(\%)\end{array}$} \\
\hline & Positive & Negative & & \\
\hline \multicolumn{5}{|l|}{ STAT } \\
\hline Positive & 84 & 301 & 95.45 & 84.95 \\
\hline Negative & 4 & 1699 & & \\
\hline Total & 88 & 2000 & & \\
\hline \multicolumn{5}{|l|}{ RBPT } \\
\hline Positive & 65 & 198 & 73.86 & 90.10 \\
\hline Negative & 23 & 1802 & & \\
\hline Total & 88 & 2000 & & \\
\hline \multicolumn{5}{|l|}{$\begin{array}{l}\text { STAT+RBPT (dual } \\
\text { positive) }\end{array}$} \\
\hline Positive & 61 & 186 & 100 & 90.06 \\
\hline Negative & 0 & 1687 & & \\
\hline Total & 61 & 1837 & & \\
\hline \multicolumn{5}{|l|}{$\operatorname{IgM}$} \\
\hline Positive & 51 & 110 & 57.95 & 94.50 \\
\hline Negative & 37 & 1890 & & \\
\hline Total & 88 & 2000 & & \\
\hline \multicolumn{5}{|l|}{$\operatorname{IgG}$} \\
\hline Positive & 9 & 21 & 10.22 & 98.95 \\
\hline Negative & 79 & 1979 & & \\
\hline Total & 88 & 2000 & & \\
\hline \multicolumn{5}{|l|}{$\begin{array}{l}\text { IgM+IgG (dual } \\
\text { positive) }\end{array}$} \\
\hline Positive & 4 & 3 & 11.11 & 99.84 \\
\hline Negative & 32 & 1872 & & \\
\hline Total & 36 & 1875 & & \\
\hline
\end{tabular}

PCR: Polymerase chain reaction, IgM: Immunoglobulin M,

IgG: Immunoglobulin G, RBPT: Rose Bengal plate test, STAT: Serum tube agglutination test

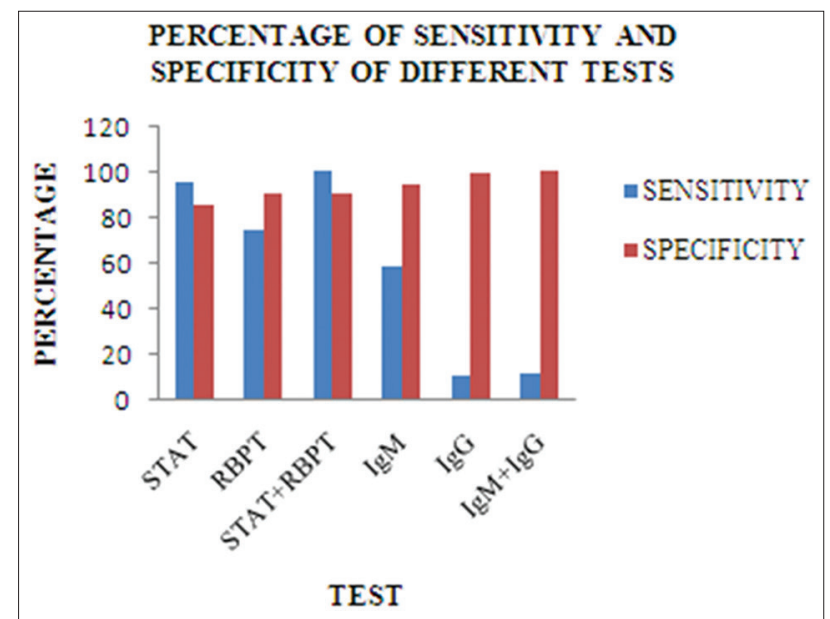

Fig. 3: The comparison among sensitivity and specificity of all the serological tests with respect to polymerase chain reaction

of lipopolysaccharide with Salmonella spp., Escherichia coli 0116 and 0157, Pseudomonas maltophilia, Yersinia enterocolitica 0: 9, and some other microbes [11]. The present study was done by several serological tests and PCR, and the tests were compared for their sensitivity and specificity for diagnosis of brucellosis taking PCR as gold standard test.
Further analysis was done to find more sensitive and specific tests for brucellosis diagnosis.

As clinical presentation of brucellosis is nonspecific and shows very complex clinical manifestation, a battery of tests may be ideal for diagnosis of brucellosis. Therefore, we had done all the serological tests and PCR, and then, serological tests were compared with PCR for finding the most sensitive and specific test for the diagnosis of brucellosis. From the result, we found that combination of STAT and RBPT showed the highest sensitivity as well as high specificity. Although the combination of IgM and IgG ELISA showed the highest specificity (99.84\%), it was low sensitive than STAT with RBPT dual positive cases. Furthermore, Metri et al. [12] reported RBPT has a close relation with STAT in the diagnosis of human brucellosis.

\section{CONCLUSION}

From this study, it can be concluded that in case of diagnosis of agglutinating antibodies, we can combine both (STAT and RBPT) tests for highest sensitivity and followed by diagnosis of non-agglutinating antibodies through ELISA test for the highest specificity.

\section{ACKNOWLEDGMENT}

We would like to acknowledge the grant received from the Government of India (Department of Biotechnology, DBT sanction order No. 102/ IFD/SAN/3141/2012-2013) and also we would like to thank all laboratory staffs working in Brucella Research Laboratory of Peerless Hospital and B.K. Roy Research Centre for their cooperation in this work.

\section{REFERENCES}

1. Sathyanarayan MS, Suresh D, Suresh BS, Krishna S, Mariraj J, Surekha SA, et al. A comparative study of agglutination tests, blood culture and ELISA in the laboratory diagnosis of human brucellosis. Int J Biol Med Res 2011;2(2):569-72.

2. Saha S, Gupta D, Das S. Autooimmuno changes in human brucellosis. Int J Biopharm 2013;4(2):131-4.

3. Prakash P, Bhansali S, Gupta E, Kothari D, Mathur A, Ambuwani S. Epidemiology of brucellosis in high risk group and PUO patients of Western-Rajasthan. Natl J Community Med 2012;3(1):61-5.

4. Smits HL, Kadri SM. Brucellosis in India: A deceptive infectious disease. Indian J Med Res 2005;122(5):375-84.

5. Hassanain AN, Ahmed MW. Efficiency of serological tests in comparison with PCR for diagnosis of brucellosis. World J Med Sci 2012;7(4):243-7.

6. Mangalgi SS, Sajjan GA, Mohite TS. Brucellosis: A cause for pyrexia of unknown origin. Int J Biol Med Res 2012;3(3):2054-5.

7. Ghatak S, Muthukumaran RB, Nachimuthu SK. A simple method of genomic DNA extraction from human samples for PCR-RFLP analysis. J Biomol Tech 2013;24(4):224-31.

8. Joshi M, Deshpande JD. Polymerase chain reaction: Methods, principles and application. Int J Biomed Res 2010;1(5):81-97.

9. Akobeng AK. Understanding diagnostic tests 1 : Sensitivity, specificity and predictive values. Acta Paediatr 2007;96(3):338-41.

10. Matovic K, Asanin R, Radojicic S, Lako B, Zarkovic A. Examination of sensitivity and specificity of some serological tests in diagnostics of bovine brucellosis. Acta Vet (Beograd) 2008;58:467-76.

11. Yohannes M, Gill JP, Ghatak S, Singh DK, Tolosa T. Comparative evaluation of the Rose Bengal plate test, standard tube agglutination test and complement fixation test for the diagnosis of human brucellosis. Rev Sci Tech 2012;31(3):979-84.

12. Metri BC, Baragundi MC, Jyothi P, Lava R, Basavarajappa, Hanumanthapa AR, et al. Seroprevelance of brucellosis in Davangere, Karnataka. J Clin Diagn Res 2011;5(1):41-4. 